\title{
COVID-19 and EBV Co-Infection in a Child
}

\section{Elda Skenderi, Admir Sulovari, Gjeorgjina Kuli-Lito, Nilsa Shahini, Griselda Toci, Ada Pema}

University Hospital Center "Mother Teresa", Tirana, Albania

Email: elda_skenderi@yahoo.com

How to cite this paper: Skenderi, E., Sulovari, A., Kuli-Lito, G., Shahini, N., Toci, G. and Pema, A. (2021) COVID-19 and EBV Co-Infection in a Child. Journal of Biosciences and Medicines, 9, 20-27.

https://doi.org/10.4236/jbm.2021.95003

Received: April 13, 2021

Accepted: May 16, 2021

Published: May 19, 2021

Copyright (c) 2021 by author(s) and Scientific Research Publishing Inc. This work is licensed under the Creative Commons Attribution International License (CC BY 4.0).

http://creativecommons.org/licenses/by/4.0/ (c) (i) Open Access

\begin{abstract}
Coronavirus disease 2019 (COVID-19) is caused by severe acute respiratory syndrome coronavirus 2 (SARS-CoV-2), reported first in December 2019 in Wuhan, China. The virus soon spread all over the world and the World Health Organization (WHO) declared a global pandemic on March 11, 2020. At the beginning of the outbreak, infections were more common in adults then in children; however, in the following months, the number of pediatric infection cases increased significantly. The disease in children is less severe, but occasionally it may be complicated with Multisystem Inflammatory Syndrome. Some of the symptoms and signs may be overlapped with other infectious diseases of the childhood and confound the appropriate diagnosis. A high index of suspicion must be maintained in children while making a diagnosis. We report the case of a 5 years old presented with COVOD-19 and EBV co-infection.
\end{abstract}

\section{Keywords}

COVID-19, EBV, Pandemic, Infection, Children

\section{Introduction}

Coronavirus disease 2019 (COVID-19) is caused by severe acute respiratory syndrome coronavirus 2 (SARS-CoV-2), reported first in December 2019 in Wuhan, Hubei province of China. The virus soon spread through all the world and the World Health Organization (WHO) declared a global pandemic on March 11, 2020. Since then, in March 15, 2021, confirmed COVID-19 infections numbered over 119 million people worldwide and have resulted in over 2.6 million deaths. The first case of COVID-19 in children was confirmed in Shenzhen, China on January 20, 2020. At the beginning of the outbreak, COVID-19 infections were more common in adults then in children; however, in the following months, the number of pediatric infection cases increased significantly. Most cases in children are mild and treatment consists in supportive care; only a small 
number need hospitalization and mortality rate is low $<0.1 \%$ of diagnosed children [1] [2] [3] [4]. As we are discovering each day more about SARS-CoV-2 infection, differences between adults and pediatric disease are probably due to changes within both immune function and the angiotensin-converting enzyme (ACE) 2 receptor, used by the virus to enter type II pneumocytes in the lung. The immune system of children is highly prepared to novel pathogens, due to high levels of innate IgM antibodies with broad reactivity, in addition to the production of the anti-inflammatory interleukin (IL)-10 by neonatal B cells [5]. Other probable explanations are alternations in $\mathrm{T}$ cell populations in adults due to continuous antigen stimulation and thymic involution, varied levels of ACE-2 expression in children, and the simultaneous presence of other viruses in the respiratory mucosa of children, competing with SARS-CoV-2 [6]. Besides, all this children have fewer comorbidities and a stronger pulmonary regenerative potential than adults.

\section{Case Report}

A 5 years old male admitted to the University Hospital Center of Tirana with a history of 2 week fever. He was treated with oral antibiotics by a local clinic for acute tonsillitis, but fever persisted and cough, diarrhea and fatigue become disturbing in the following days. No family contact with COVID-19 positive individuals was reported. On physical examination he appeared ill. The pharynx was injected with swollen tonsils without exudates. The child was tachypneic, respiratory frequency was 40 breaths/min, and oxygen saturation $94 \%$, fine rales were found bilaterally in auscultation. Gastrointestinal manifestations consisted of abdominal pain and diarrhea. The abdomen was soft, not distended, bowel sounds were present. Nor rash on the skin, neither swollen hands or feet, were observed.

Laboratory investigations on admission revealed a blood cell count WBC 11,400 cells $/ \mathrm{mm}^{3}$ (54.7\% neutrophils and 34.1\% lymphocytes), RBC 4,270,000 cells $/ \mathrm{mm}^{3}$, Hemoglobin level $11.5 \mathrm{~g} / \mathrm{dL}$, Hematocrit value $33.1 \%$, Platelet count $1,072,000$ cells $/ \mathrm{mm}^{3}$, Erythrocyte sedimentation rate $28 \mathrm{~mm} / \mathrm{h}(<15 \mathrm{~mm} / \mathrm{h})$, Aspartat aminotransferase $27 \mathrm{U} / \mathrm{L}(14-35 \mathrm{U} / \mathrm{L})$, Alanin aminotransferase $15 \mathrm{U} / \mathrm{L}$ (9 - $24 \mathrm{U} / \mathrm{L})$, Creatin kinase $55 \mathrm{U} / \mathrm{L}$ (30 - $200 \mathrm{U} / \mathrm{L})$, Blood urea nitrogen 25.3 $\mathrm{mg} / \mathrm{dL}(15-36 \mathrm{mg} / \mathrm{dL})$, Creatinine $0.53 \mathrm{mg} / \mathrm{dL}(0.44-0.64 \mathrm{mg} / \mathrm{dL})$, Serum total protein $7.9 \mathrm{~g} / \mathrm{dL}(6-8 \mathrm{~g} / \mathrm{dL})$, Albumin $4.5 \mathrm{mg} / \mathrm{dL}(3.2-4.5 \mathrm{mg} / \mathrm{dL})$, C reactive protein $1.16 \mathrm{mg} / \mathrm{dL}(<0.5 \mathrm{mg} / \mathrm{dL})$, D - dimer $300 \mathrm{mg} / \mathrm{dL}(<198 \mathrm{mg} / \mathrm{dL})$, Fibrinogen activity $331 \mathrm{mg} / \mathrm{dL}$ (160 - $390 \mathrm{mg} / \mathrm{dL})$, PT quick time 106\% (70\% - 110\%), Prothrombin time/international normalized ratio (INR) 0.96 (0.85 - 1.15), aPTT $28.7 \mathrm{sec}(24-35 \mathrm{sec})$.

Abdominal ultrasonography revealed an enlarged liver $121 \mathrm{~mm}$ and lymphadenitis $14 \times 7 \mathrm{~mm}$. Chest radiography revealed bilateral peribronchial thickening and peribronchial opacities. Reverse transcriptase PCR for COVID-19 was negative, IgM antibodies for COVID-19 were positive and IgG antibodies for 
COVID-19 were negative. As the child did not fulfill all the criteria to meet the diagnosis of "Multisystem Inflammatory Syndrome in Children", but the symptoms persisted and some of the inflammatory parameters were increased, there was suspected that another infectious agent could have complicated the scenery. The EBV panel result indicated acute primary infection IgM antibodies against viral capsid antigen (VCA) were positive, whereas VCA-IgG antibodies were negative.

Thrombocytosis was assumed to be of reactive origin due to excessive inflammation generated by the combination of two infectious agents COVID-19 and EBV. Once the combined diagnosis was confirmed therapeutic approach was symptomatic. Fever subsided gradually, lymphadenitis was reduced and the child appeared playful. Thrombocytosis subsided after a couple of weeks too (Table 1).

\section{Discussion}

As SARS-CoV-2 disease is emerging and the world is in the middle of the pandemic, it is not easy for the pediatrician, to differ between COVID-19 infection and other potential viruses of childhood. Almost all medical resources are directed towards COVID-19 infections and still it's challenging to make a diagnosis or predicts its complications in children.

It is already known that fewer cases of COVID-19 disease have been diagnosed in children than in adults. The majority of the pediatric cases have been mild, but severe illness has been reported in $2.5 \%$ of pediatric cases in China, according to the World Health Organization [7]. The most reported signs and symptoms in children are cough, pharyngeal erythema and fever. Other less common signs and symptoms include diarrhea, fatigue, rhinorrhea, vomiting and nasal congestion. A small percent presents with severe disease, dyspnea, persistent high fever, lethargy, increased levels of enzymes [4]. Since May 2020, several highly endemic countries reported a high incidence of multisystem inflammatory syndrome (MIS) in children [8] [9] [10] [11]. All include fever, elevated inflammatory markers, and organ dysfunction not attributed to another infectious cause. The median interval from COVID-19 symptom onset to MIS onset is 25 days [12]. The higher rate of positive serologic tests compared with nasopharyngeal reverse transcription-polymerase chain reaction (RT-PCR) is

Table 1. Clinical outcome of the patient.

\begin{tabular}{ccccc}
\hline Hositalization time & 0 week & 1 week & 2 weeks & 6 weeks \\
\hline WBC & $11,400 \mathrm{cell} / \mathrm{mm}^{3}$ & $15,100 \mathrm{cell} / \mathrm{mm}^{3}$ & $9200 \mathrm{cell} / \mathrm{mm}^{3}$ & $8600 \mathrm{cell} / \mathrm{mm}^{3}$ \\
Lymphocytes & $34.1 \%$ & $51.3 \%$ & $56.2 \%$ & $31.4 \%$ \\
CRP & 1.16 & 0.97 & 0.6 & 0.05 \\
Thrombocytes & $1,072,000 \mathrm{cell} / \mathrm{mm}^{3}$ & $821,000 \mathrm{cell} / \mathrm{mm}^{3}$ & $683,000 \mathrm{cell} / \mathrm{mm}^{3}$ & $464,000 \mathrm{cell} / \mathrm{mm}^{3}$ \\
D-dimer & $300 \mathrm{mg} / \mathrm{dL}$ & $201 \mathrm{mg} / \mathrm{dL}$ & $190 \mathrm{mg} / \mathrm{dL}$ & $158 \mathrm{mg} / \mathrm{dL}$ \\
\hline
\end{tabular}


suggestive of a late complication of the disease [8] [12] [13] [14] [15]. Besides fever, the most common presentations of MIS are gastrointestinal (diarrhea, vomiting, abdominal pain), cardiovascular, mucocutaneous (rash, mucus membrane changes, conjunctival injection), respiratory (including sore throat), headache, and limb and periorbital edema [11] [12] [13]. Associated laboratory findings are elevated inflammation markers (neutrophilia, C-reactive protein, ferritin, erythrocyte sedimentation rate), thrombocytopenia, lymphopenia, elevated troponin and N-terminal pro-B-type natriuretic peptide (NT-proBNP), hypertriglyceridemia, and elevated D-dimer and fibrinogen (Table 2, Figure 1) [16]. Some patients meet the criteria for macrophage activation syndrome (MAS).

As the presenting child had a negative reverse transcriptase protein chain reaction (RT-PCR) for COVID-19 but a positive serology for COVID-19 (increased IgM levels, which are higher during weeks 2 - 3 of illness), prolonged fever $>10$ days, cough, diarrhea, fatigue, cervical lymphadenopathy, pharyngeal erythema

Table 2. CDC case definition for multisystem inflammatory syndrome in children (MIS-C).

1) An individual aged $<21$ years with

2) Clinical criteria:

_ A minimum 24-h history of subjective or objective fever_ 38.0_C AND

_ Severe illness necessitating hospitalization AND

- Two or more organ systems affected (i.e., cardiac, renal, respiratory, hematologic, gastrointestinal, dermatologic, neurological)

3) Laboratory evidence of inflammation

_ One or more of the following: an elevated CRP, ESR, fibrinogen, procalcitonin, D-dimer, ferritin, LDH, or IL-6; elevated neutrophils or reduced; low albumin

4) Laboratory or epidemiologic evidence of SARS-CoV-2 infection _ Positive SARS-CoV-2 testing by RT-PCR, serology, or antigen OR

_ COVID-19 exposure within 4 weeks prior to onset of symptoms

5) No alternative diagnosis

Abbreviations: CDC, Centers for Disease Control; CRP, C-reactive protein; ESR, erythrocyte sedimentation rate; $\mathrm{LDH}$, lactate dehydrogenase; RT-PCR, reverse transcriptase polymerase chain reaction; SARS-CoV-2, severe acute respiratory syndrome coronavirus-2

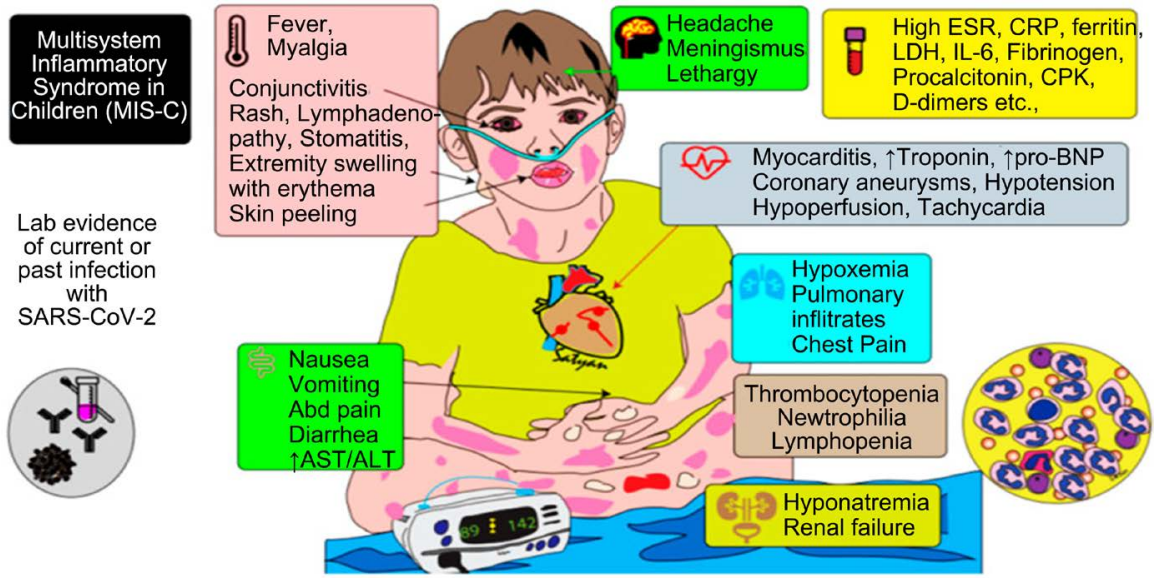

Figure 1. Infographic showing CDC criteria for the diagnosis of MIS-C. 
and some of the inflammatory proteins increased such as CRP and d-Dimer, initially was presumed to be in front of a MIS-C. However there were present some confounding elements on laboratory results non consistent with MIS-C such as lymphocytosis and thrombocytosis. A consistent pattern of laboratory abnormalities has not yet been identified in children with confirmed COVID-19, however, a common laboratory abnormalities among hospitalized patients include lymphopenias (due to destruction of infected $\mathrm{T}$ lymphocyte cells) and thrombocytopenia in cognition with other coagulation parameters abnormalities.

On the other hand Epstein-Barr virus (EBV) which is not a rare agent causing disease in children manifests overlapping symptoms with COVID-19. EBV is ubiquitous in nature and infects a large fraction of the world population. In young children primary infection is usually asymptomatic or produces an acute illness that is often not recognized as being due to EBV or may be also presented with the full blown clinic of Infectious Mononucleosis; fever, pharyngitis, lymphadenopathy, hepato-splenomegaly and fatigue (Figure 2) [17]. The median duration of infectious mononucleosis is 16 days, which is much longer than the duration of most acute viral illnesses, recovery is gradual. A potent innate and adaptive immune response occurs during primary EBV infection. The innate immune system is an important first line of defense against viral infections. Many inflammatory cytokines such as tumor necrosis factor alpha (TNF- $\alpha$ ), interleukin-6 (IL-6), IL- $1 \beta$ and IFN- $\gamma$ are found in the sera of patients infected with EBV and COVID-19 too. IFN- $\gamma$ is thought to be important for control of EBV infection [18] [19]. High levels of IFN- $\gamma$ likely contribute to the symptoms experienced during infectious mononucleosis, as this cytokine is known to cause

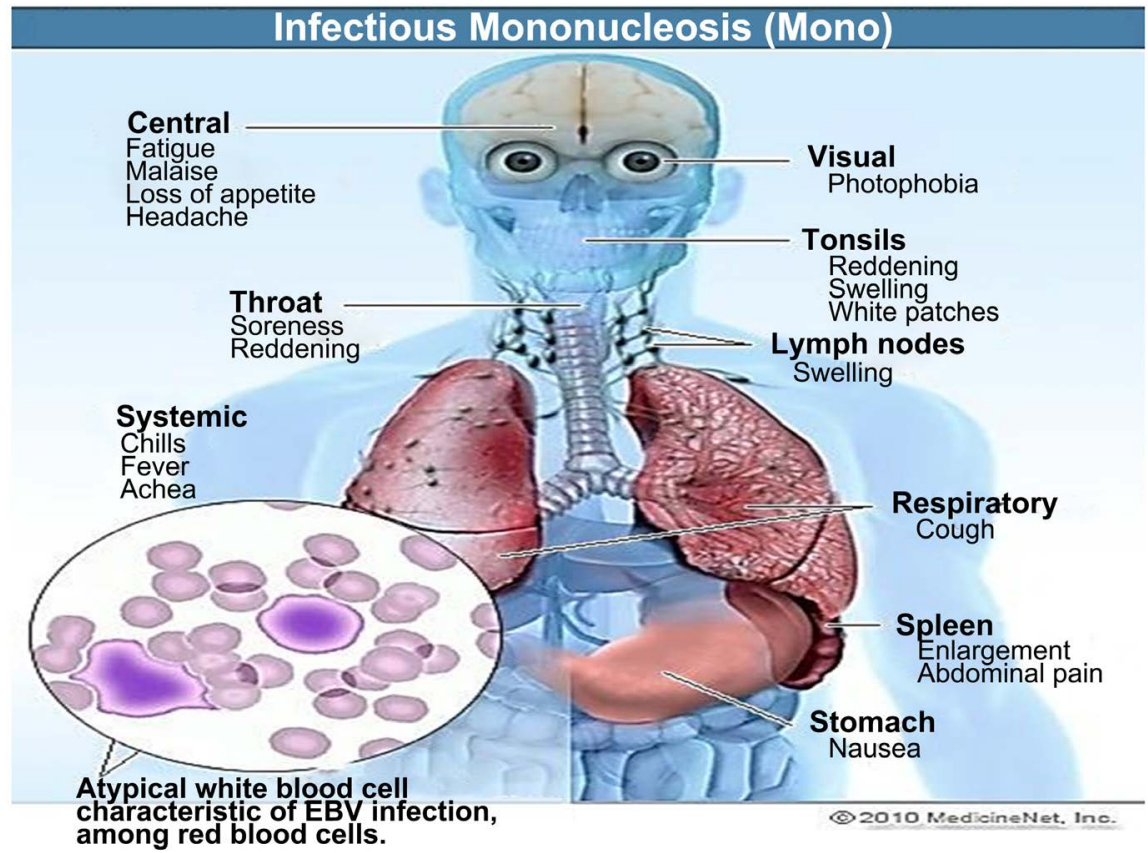

Figure 2. Infographic showing infectious mononucleosis. 
headache, fatigue, and fever [20]. Both CD4 and CD8 T cells make a robust response to EBV antigens, the massive lymphocytosis in the blood that characterizes infectious mononucleosis is thought to consist largely of CD8 T cells specific for EBV lytic antigens [21]. Both agents EBV and COVID-19 modulate the immune system.

Thrombocytosis is not typical in EBV or COVID-19 infection otherwise they are companied by mild thrombocytopenia. Thrombocytosis in children are usually reactive, particularly common during recovery phase of an infection or inflammation and are usually transient and subsides when the primary stimulus ceases. Reactive thrombocytosis is usually mediated by increased release of numerous cytokines in response to infections. A wide range of cytokines may participate in the stimulation of platelet production, IL-3, IL-11, granulocyte-macrophage colony-stimulating factor, erythropoietin but the most imported role is plaid by thrombopoietin and IL-6 which are initially elevated in response to infections [22]. In this case thrombocytosis is an exaggerated physiologic response to the combined infections. Despite the strikingly high platelet count, sometimes exceeding 1,000,000 cells $/ \mathrm{mm}^{3}$, thrombotic and/or hemorrhagic complications are highly exceptional.

\section{Conclusion}

COVID-19 has inflicted all the world population. The number of infected children is progressively increasing. The disease in children is less severe, but sometimes it may be complicated with Multisystem Inflammatory Syndrome. Some of the symptoms and signs may be overlapped with other infectious diseases of the childhood, such as EBV and respiratory viruses, and confound the appropriate diagnosis. So a high index of suspicion must be maintained in children while making a diagnosis.

\section{Acknowledgements}

We thank Prof. Anila Godo for critical reading of the manuscript.

\section{Conflicts of Interest}

The authors declare no conflicts of interest regarding the publication of this paper.

\section{References}

[1] Dong, Y., Mo, X., Hu, Y., Qi, X., Jiang, F. and Jiang, Z. (2020) Epidemiology of COVID-19 among Children in China. Pediatrics, 145, e20200702. https://doi.org/10.1542/peds.2020-0702

[2] Bialek, S., Gierke, R., Hughes, M., McNamara, L., Pilishvili, T. and Skoff, T. (2020) Coronavirus Disease 2019 in Children-United States, February 12-April 2, 2020. Morbidity and Mortality Weekly Report, 69, 422-426. https://www.cdc.gov/mmwr/volumes/69/wr/mm6914e4.htm https://doi.org/10.15585/mmwr.mm6914e4 
[3] Livingston, E. and Bucher, K. (2020) Coronavirus Disease 2019 (COVID-19) in Italy. JAMA, 323, 1335-1335. https://www.iss.it/infografiche

[4] Lu, X., Zhang, L., Du, H., Zhang, J., Li, Y.Y., Qu, J., et al. (2020) SARS-CoV-2 Infection in Children. The New England Journal of Medicine, 382, 1663-1665. https://doi.org/10.1056/NEJMc2005073

[5] Carsetti, R., Quintarelli, C., Quinti, I., Piano Mortari, E., Zumla, A., Ippolito, G., et al. (2020) The Immune System of Children: The Key to Understanding SARS-CoV-2 Susceptibility? The Lancet Child \& Adolescent Health, 4, 414-416. https://doi.org/10.1016/S2352-4642(20)30135-8

[6] Yuki, K., Fujiogi, M. and Koutsogiannaki, S. (2020) COVID-19 Pathophysiology: A Review. Clinical Immunology, 215, Article ID: 108427.

https://pubmed.ncbi.nlm.nih.gov/32325252 https://doi.org/10.1016/j.clim.2020.108427

[7] Toubiana, J., Poirault, C., Corsia, A., Bajolle, F., Fourgeaud, J., Angoulvant, F., et al. (2020) Kawasaki-Like Multisystem Inflammatory Syndrome in Children during the Covid-19 Pandemic in Paris, France: Prospective Observational Study. BMJ, 369, m2094. https://doi.org/10.1136/bmj.m2094

[8] Verdoni, L., Mazza, A., Gervasoni, A., Martelli, L., Ruggeri, M., Ciuffreda, M., et al. (2020) An Outbreak of Severe Kawasaki-Like Disease at the Italian Epicentre of the SARS-CoV-2 Epidemic: An Observational Cohort Study. The Lancet, 395, 1771-1778. https://doi.org/10.1016/S0140-6736(20)31103-X

[9] Rauf, A., Vijayan, A., John, S.T., Krishnan, R. and Latheef, A. (2020) Multisystem Inflammatory Syndrome with Features of Atypical Kawasaki Disease during COVID-19 Pandemic. Indian Journal of Pediatrics, 87, 745-747.

https://doi.org/10.21203/rs.3.rs-29369/v1

[10] Riphagen, S., Gomez, X., Gonzalez-Martinez, C., Wilkinson, N. and Theocharis, P. (2020) Hyperinflammatory Shock in Children during COVID-19 Pandemic. The Lancet, 395, 1607-1608. https://www.ncbi.nlm.nih.gov/pmc/articles/PMC7204765 https://doi.org/10.1016/S0140-6736(20)31094-1

[11] Godfred-Cato, S., Bryant, B., Leung, J., Oster, M.E., Conklin, L., Abrams, J., et al. (2020) COVID-19-Associated Multisystem Inflammatory Syndrome in Children-United States, March-July 2020. MMWR Morbidity and Mortality Weekly Report, 69, 1074-1080. https://doi.org/10.15585/mmwr.mm6932e2 http://www.cdc.gov/mmwr/volumes/69/wr/mm6932e2.htm?s_cid=mm6932e2_w

[12] Feldstein, L.R., Rose, E.B., Horwitz, S.M., Collins, J.P., Newhams, M.M., Son, M.B.F., et al. (2020) Multisystem Inflammatory Syndrome in U.S. Children and Adolescents. The New England Journal of Medicine, 383, 334-346.

[13] Whittaker, E., Bamford, A., Kenny, J., Kaforou, M., Jones, C.E., Shah, P., et al. (2020) Clinical Characteristics of 58 Children with a Pediatric Inflammatory Multisystem Syndrome Temporally Associated with SARS-CoV-2. JAMA, 324, 259-269. https://doi.org/10.1001/jama.2020.10369

[14] WHO (2020) Report of the WHO-China Joint Mission on Coronavirus Disease 2019 (COVID-19). World Health Organization, Geneva.

https://www.who.int/publications-detail/report-of-the-who-china-joint-mission-on -coronavirus-disease-2019-(covid-19)

[15] Nakra, N.A., Blumberg, D.A., Herrera-Guerra, A. and Lakshminrusimha, S. (2020) Multi-System Inflammatory Syndrome in Children (MIS-C) Following SARS-CoV-2 Infection: Review of Clinical Presentation, Hypothetical Pathogenesis, and Proposed Management. Child (Basel, Switzerland), 7, 69. 
http://www.ncbi.nlm.nih.gov/pubmed/32630212 https://doi.org/10.3390/children7070069

[16] Natasha, N.A., Dean, B.A., Angel, H.-G. and Satyan, L. (2020) Multi-System Inflammatory Syndrome in Children (MIS-C) Following SARS-CoV-2 Infection: Review of Clinical Presentation, Hypothetical Pathogenesis, and Proposed Management. https://www.mdpi.com/journal/children https://doi.org/10.3390/children7070069

[17] Melissa, S.C. and William, S.C. (2020) Infectious Mononucleosis. http://medicinenet.com/infectious_mononucleosis/article.htm

[18] Lee, K.S., Groshong, S.D., Cool, C.D., Kleinschmidt-DeMasters, B.K. and van Dyk, L.F. (2009) Murine Gammaherpesvirus 68 Infection of IFNgamma Unresponsive Mice: A Small Animal Model for Gammaherpesvirus-Associated B-Cell Lymphoproliferative Disease. Cancer Research, 69, 5481-5489.

https://doi.org/10.1158/0008-5472.CAN-09-0291

[19] Weck, K.E., et al. (1997) Murine Gamma-Herpesvirus 68 Causes Severe Large-Vessel Arteritis in Mice Lacking Interferon-Gamma Responsiveness: A New Model for Virus-Induced Vascular Disease. Nature Medicine, 3, 1346-1353.

https://doi.org/10.1038/nm1297-1346

[20] Schiller, J.H., et al. (1990) Biological and Clinical Effects of the Combination of Beta- and Gamma-Interferons Administered as a 5-Day Continuous Infusion. Cancer Research, 50, 4588-4594.

[21] Hislop, A.D., Taylor, G.S., Sauce, D. and Rickinson, A.B. (2007) Cellular Responses to Viral Infection in Humans: Lessons from Epstein-Barr Virus. Annual Review of Immunology, 25, 587-617. https://doi.org/10.1146/annurev.immunol.25.022106.141553

[22] Zheng, S.Y., Xiao, Q.Y., Xie, X.H., et al. (2016) Association between Secondary Thrombocytosis and Viral Respiratory Tract Infections in Children. Scientific Reports, 6, Article No. 22964. https://doi.org/10.1038/srep22964 